\title{
Water Truck Routing Optimization in Open Pit Mines Using the General Algebraic Modelling System Approach
}

\author{
Mohammad Hossein Sadat Hosseini Khajouei ${ }^{1}$ (D), Maryam Lotfi ${ }^{2(\bowtie)}$, \\ Ahmad Ebrahimi ${ }^{1}$, and Soheil Jafari ${ }^{3}$ \\ ${ }^{1}$ Department of Industrial Management, IAU, Science and Research Branch, Tehran, Iran \\ 2 Cardiff Business School, Cardiff University, Cardiff, UK \\ Lotfimacardiff.ac.uk \\ 3 School of Aerospace, Transport and Manufacturing (SATM), \\ Cranfield University, Cranfield, UK
}

\begin{abstract}
This paper presents a methodological approach for routing optimization in open pit mines which is a trending topic for dust emission reduction in mining process. In this context, the aim of the research and its contribution to the knowledge is firstly described based on a comprehensive literature survey in the field. Then, as an arc routing problem, the mathematical model for the process is generated including the objective function, minimizing the total distance traveled by the water truck fleets, practical constraints that should be met and the used assumptions. Finally, the formulated optimization problem solved employing General Algebraic Modelling System (GAMS) approach respect to the nature of the mathematical equations. The tested results by simulations discussed to confirm the effectiveness of the proposed method in dealing with the in-hand problem. This methodological approach could be used in optimization of other similar engineering problem as well.
\end{abstract}

Keywords: Routing optimization · Open pit mines · GAMS · Arc routing problem

\section{Introduction}

Mining as a process of extracting minerals from the ground with the aim of profitability includes five main steps: prospection, exploration, development, exploitation and reclamation, in which making the strategic decisions is indispensable to enhance the performance of the whole process.

Increasing the mineral resources extraction and subsequently, surface mining leads to dust emission containing Silica in mines and their suburbs. Inhaling of dust containing Silica as a mineral with the most plenty in the earth causes respiratory diseases such as silicosis and lung cancer. As a potential solution, utilizing an appropriate water trucks fleet in the mines' roads and ramps in loading, hauling, vehicle travel and blasting processes would result in dust control. The other advantages of water fleet implementation 
in mines as a sustainable approach in mining engineering, particularly in open pit mines could be: to provide the healthier working environment, increased visibility of roads, tires' lifetime and machinery maintenance cost reduction.

There are numerous mines with a high diversification of minerals in which their exploitation, volume and dimension of production are dramatically increasing. Hence, application of an optimized procedure of fleet of water truck that loads water from the set of predetermined stations and prevents the formation of dust by traversing the haul roads and spraying them is a vital step in mining strategic decision process. The objective of present paper is to apply an Equation-Based Modeling (EBM) approach in the field of mining engineering and consequently to propose an optimized model to specify optimal routes for each homogeneous water trucks in open pit mines.

The remainder of this paper is as follows. Section 2 explains the applications of the operation research techniques in mining engineering problems to describe the gap in the literature that is aimed in this paper. Section 3 presents a review of the related literature. Section 4 is devoted to implementation of the mathematical modeling. Section 5 discusses sensitivity analysis and findings and finally, Sect. 6 presents the conclusion. This paper aims to respond to the issue of how to provide a model for water truck routing problem using a system approach tool.

\section{Application of Operation Research Techniques in Mining Engineering}

Use of operational research (OR) methodologies in planning related to extraction and exploration operations of surface and underground mines, including pit design, production planning in short and long-term horizons or fleet planning of transport and loading machines dates back to the 1960s Newman (2010). It is noteworthy that rare studies have been conducted to dispatch a fleet of water trucks as one of the pillars to control the phenomenon of dust emission. This area can be studied as a sustainable approach in mining engineering. Many labors and employees in open pit mines are constantly suffering from diseases caused by the spread of silica dust.

Based on a literature review, considering the type of process, optimization of mining and haulage is implemented commonly by queue theory and simulation. Due to the complexity and large dimensions of pit design and production scheduling, heuristic and meta-heuristic methods employed. Linear programming is a usual method for truck allocating-dispatching in the shovel-truck systems. Dynamic programming for productivity improvement of shovel-truck systems and integer programming, goal programming and non-linear programming applied for extraction scheduling in underground mines, coal mines especially. Newly, application of mathematical modeling with the approach of vehicle routing problem in determination of final limits of pit with the Lerch and Grossman method is implemented. In the realm of mining engineering, application of arc routing problem for water truck fleet with the approach of dust emission decreasing is less observed. Table 1 categorizes different OR techniques used in different aspects of the mining problems. Newman et al. (2016) proposed an integer programing for optimizing the open pit to underground mining transition and solved their problem by an ad-hoc branch-and-bound approach. 
Gupta et al. (2018) formulated an integrated multi objective model in which estimation of weights of different types of vehicles available for transportation in coal mine industry is calculated by the Analytic Hierarchy Process (AHP) and Data Envelopment Analysis (DEA) technique is applied to calculate efficiency privileges of vehicles on different routes of a transportation system.

Table 1. Application of OR techniques in mining problems

\begin{tabular}{l|l|l}
\hline & Mining engineering sections & OR methodology \\
\hline 1 & Optimization of hauling in open pit mining & $\begin{array}{l}\text { Queue theory } \\
\text { Simulation }\end{array}$ \\
\hline 2 & Open pit mine design as a complex problem & Heuristic and meta heuristic algorithm \\
\hline 3 & $\begin{array}{l}\text { Dump truck allocation considering shovel } \\
\text { idling }\end{array}$ & Linear programming \\
\hline 4 & To determine the final limit of pit & Vehicle routing problem \\
\hline 5 & $\begin{array}{l}\text { Time scheduling for mineral production in } \\
\text { underground and open pit mining }\end{array}$ & Meta heuristic algorithm \\
\hline 6 & $\begin{array}{l}\text { Production efficiency improvement in } \\
\text { truck-shovel systems }\end{array}$ & Dynamic programming \\
\hline 7 & $\begin{array}{l}\text { Time scheduling for underground mines } \\
\text { production }\end{array}$ & Mix integer programming \\
\hline 8 & $\begin{array}{l}\text { Time scheduling for underground coal mines } \\
\text { extraction }\end{array}$ & $\begin{array}{l}\text { Non-Linear programming } \\
\text { Goal programming }\end{array}$ \\
\hline 9 & Dump truck dispatching system & Linear programming \\
\hline
\end{tabular}

According to Table 1, there is a gap in the literature for consideration of the dust emission control in open pit mining. On the other side, propounding Arc Routing Problem for services that are related to roads of mines, for instance water truck services, can be considered as an innovation in the realm of OR method deployment in mining engineering. This paper will focus on these gaps to propose a new solution for gaining safe atmosphere in mines for labors' health.

\section{Literature Review and Background of the Problem}

In the present study, the problem of wetting down service to a set of roads in the open pit mine network using a fleet of water trucks with bounded capacity is considered as an Arc Routing Problem (ARP). Refilling station is located at a central depot and the objective of the problem is to minimize the total traveling distance. Therefore, in this section, the literature related to the subject is briefly studied. 
Golden and Wong (1981) defined a capacitated ARP, to prepare mathematical programming formulations, to accomplish a computational complexity analysis, and to present an approximate solution strategy for this kind of problems. Eglese (1994) presented the formulation of a practical routing problem which has been implemented as a computer program to run on a microcomputer and used the formulation to explore the cost consequences of different scenarios for the gritting operation in a County.

Eiselt et al. (1995) implemented a comprehensive review on ARP including the Chinese Postman Problem (CPP) and the algorithms for its directed and undirected types, the windy postman problem (WPP), the mixed CPP and the hierarchical CPP, and also the Rural Postman Problem (RPP), the directed and undirected types of RPP, the stacker crane and capacitated ARP, considering their applications. For a more detailed study, readers are highly recommended to refer to Sachs et al. (1988) for Euler's Konigberg letters, Kwan (1962) and Edmonds and Johnson (1973) for Chinese Postman Problem (CPP), Eiselt et al. (1995) for Rural Postman Problem (RPP) and Golden and Wong (1981) for capacitated ARP as the milestones in ARP.

Generally, the ARPs could be categorized in un-capacitated and capacitated forms: Un-capacitated ARP includes determining minimum cost tours which in the most appropriate arcs are traversed at least once. Un-capacitated ARP has two major categories: CPP and RPP. If a central depot, consisting of a fleet of constrained-capacity vehicles, provides service to a subset of the streets of a network with the goal of minimizing the total cost of routing, problem capacitated ARP arises Wohlk (2008). Table 2 shows the milestones in un-capacitated Arc Routing Problem formulation.

Table 2. Milestones in un-capacitated arc routing problem formulation

\begin{tabular}{l|l}
\hline Un-capacitated ARPs (Chinese postman problem) & Reference \\
\hline Mixed CPP (MCPP) & Guan (1962) \\
\hline Windy PP (WPP) & Guan (1962) \\
\hline Hierarchical CPP (HCPP) & Dror et al. (1987) \\
\hline Generalized CPP (GCPP) & Dror et al. (2000) \\
\hline Maximum Benefit CP (MBCPP) & Pearn et al. (2003) \\
\hline CPP with time windows (CPPTW) & Eglese (2006) \\
\hline Un-capacitated ARPs (Rural Postman Problem) & Reference \\
\hline Undirected RPP & Christofieds et al. (1986) \\
\hline RPP with deadline classes & Letchford et al. (1998) \\
\hline DRPP with turn penalties and forbidden turns (DRPPTP) & Benavent et al. (1999) \\
\hline Periodic RPP & Ghiani et al. (2001) \\
\hline Profitable Arc Tour Problem (PATP) & Feillet et al. (2005) \\
\hline Prize-collecting RPP (PRPP) & Araoz et al. (2006) \\
\hline Windy RPP & Benavent et al. (2003) \\
\hline
\end{tabular}


Table 3 shows the milestones in capacitated ARP formulation. In the realm of ARP application in the road maintenance operations in cold regions and in winter, spreading of chemicals and abrasives, snow-plowing, loading snow into trucks, and hauling snow to disposal sites, including vehicle routing and depot location are investigated. Langevin et al. (2004) presented a multiple survey in which optimization models and solution algorithms for the design of winter road maintenance systems reviewed. Moreover, optimizing the total distance travelled and gritters (In terms of capacity and number), Eglese (1994) proposed routing winter gritting vehicles. The introduced model dealt with multiple depot locations. He assumed that vehicles were bounded-capacities, and roads were different in terms of priority.

Table 3. Milestones in capacitated Arc Routing Problem formulation

\begin{tabular}{l|l}
\hline Capacitated ARPs & Reference \\
\hline The Undirected Capacitated Arc Routing Problem & Golden and Wong (1981) \\
\hline CARP With Temporal Constraints or Split Deliveries & $\begin{array}{l}\text { Mullaseril (1996) } \\
\text { Dror et al. (1998) }\end{array}$ \\
\hline Capacitated Arc Routing With Several Facilities & Ghiani and Laporte (2001) \\
\hline The Mixed Capacitated ARP & Mourao and Amado (2005) \\
\hline Capacitated ARP with refill points & Amaya et al. (2007) \\
\hline
\end{tabular}

In addition, for the road maintenance operations and road network surveillance, the road network monitoring is carried out periodically. Each category of roads visited, which is already classified according to the road hierarchy, requires different monitoring during the sub-periods throughout the time horizon. (Monroy et al. 2013). With this explanation, Monroy et al. (2013) introduced the periodic CARP with irregular services. They classified PCARP into two categories: period independent demand and cost and period dependent demand and cost. Each of these classes could be consisted of irregular or regular services.

Soler et al. (2011) presented the capacitated general windy routing problem with turn penalties which is vital for real-life problems and includes many important and wellknown arc and node routing problems. (Beraldi et al. 2015) studied the general routing problem under uncertainty (demand is stochastic), in which a chance-constrained integer programming formulation was taken into account. The problem is defined based on a mixed graph theory, in which vehicles' capacity is assumed limited.

As a general case of the capacitated LRP, Karaoglan et al. (2013) considered a Capacitated LRP with Mixed Backhauls (CLRPMB). CLRPMB is defined as locating depots and finding routes of vehicles with overall cost minimization, whereas the same vehicle meets customer pickup demands and performs their delivery services. Identifying vehicles routes, Constantino et al. (2015) considered AR with a constraint to limit number of common nodes, so they introduced the MCARP with non-overlapping routes that enforces an upper bound on the number of nodes that are shared for different routes. 
Armas et al. (2018) proposed the non-smooth ARP with soft constraints in order to capture in more perceptive way realistic constraints violations arising in transportation and logistics. Gonzalez et al. (2016) introduced a simheuristics approach for solving an ARP variant in which, customers' demands are modeled as random variables. Aiming to minimize total cost, Babaee Tirkolaee et al. (2018a) proposed a mixed-integer linear programming (MILP) model was developed for the multi-trip Capacitated Arc Routing Problem (CARP) with different located depots and disposal facilities. To check the validity of the proposed model they general algebraic modelling system approach (GAMS) and CPLEX solver.

Babaee Tirkolaei et al. (2019) have addressed a novel robust bi-objective multitrip periodic capacitated arc routing problem under demand uncertainty to treat the urban waste collection problem and IWO is developed to solve the proposed model. They have mentioned that Multi Objective Invasive Weed Optimization is regarded as the best method to solve the large-sized multi-trip periodic capacitated arc routing problem. Willemse and Joubert (2019) developed local Search heuristics for Mixed Capacitated Arc Routing Problem under Time Restrictions with Intermediate Facilities (MCARPTIF), basic local search versions showed poor performance on realistically sized problem instances and three local search acceleration techniques were combined to improve its performance. They came to the conclusion that the accelerated local search can be applicable within meta-heuristics for similar problems.

Studying the uncertain nature of demand parameter and minimizing total traversed distance and total usage cost of vehicles, Babaee Tirkolaee (2018b) proposed a novel mathematical model for robust periodic capacitated arc routing problem (PCARP) considering multiple trips and drivers and crew's working time. Aiming to minimize total cost including the cost of generation and emission of greenhouse gases, the cost of vehicle usage and routing cost, Babaee Tirkolaee (2018c) addressed a multi-trip Green Capacitated Arc Routing Problem (G-CARP) and a Hybrid Genetic Algorithm (HGA) to solve the proposed model. Khajepoura et al. (2020) modeled agricultural operations as a CARP. By separating the paths into two classes of required and non-required, CARP demonstrates a field as a graph. Using CARP, no extra or invalid edge on the graph would be required. They presented an adaptive large neighborhood search (ALNS) to solve similar large scales models.

As a contribution, in the realm of mining engineering, application of arc routing problem for water truck fleet with the approach of dust emission decreasing is less observed. Therefore, this research aims to optimize the water truck routing in open pit mines to find the minimum length of arcs, the minimum required amount of water for each path and the minimum service time for each truck in each path. Hence, in the next chapter, this problem will be formulated and solved as a mathematical optimization problem.

\section{Mathematical Modeling}

Attending to machinery efficiency, environmental issues and employee healthcare vitalism, this research focused on finding optimal tours by proposing an appropriate mathematical model for water truck fleet in open pit mines with minimum traveled distance. 
Depending on the type of water truck fleet operation, instead of nodes, the roads should be serviced. So, arc routing problem is propounded, and the part of network is serviced, hence the model can be in rural postman problem category. After loading the tanks, water trucks start traveling from refilling station which located in depot (Fig. 1) and with completion of servicing or reserved water finishing, they turn back to the depot.

Let $\mathrm{G}=\left(\mathrm{N}, \mathrm{A}=\mathrm{R}_{1} \cup \mathrm{R}_{2}\right)$ be an undirected graph in which $\mathrm{N}$ is the set of nodes and $A$ is the set of arcs including subset $R_{1}$ for unidirectional roads and $R_{2}$ for two ways ones. Note here that refilling station is located in node $\mathrm{O}$ which is the depot too. The objective function includes minimization of total distance traveled by water truck fleet. Model assumptions are:

- Water trucks are homogeneous, and their capacities are known.

- The arcs can be used in unidirectional, two-way and combinational.

- All of arcs can be traveled several times but can be serviced just once and by one truck.

- Just a part of graph could be serviced.

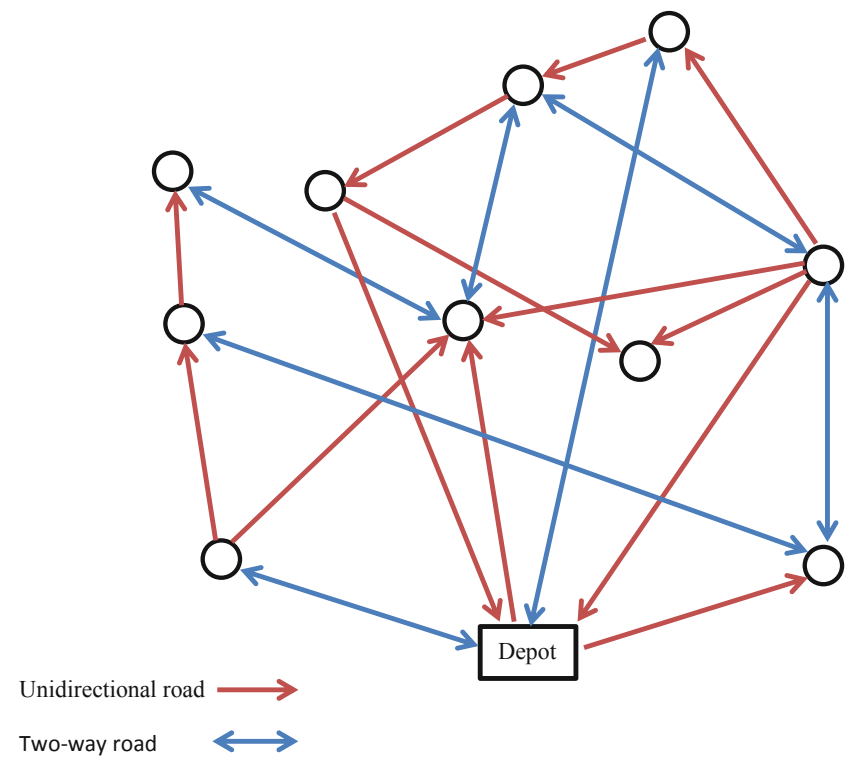

Fig. 1. Schematic of the water truck routing problem.

Figure 2 illustrates a typical format of the problem in order to define index sets, variables, and parameters as follow:

Index sets

I Set of nodes

$\mathrm{i}, \mathrm{j}$ Index of nodes

$\mathrm{K}$ Set of water trucks

$\mathrm{K}$ Index of water trucks 


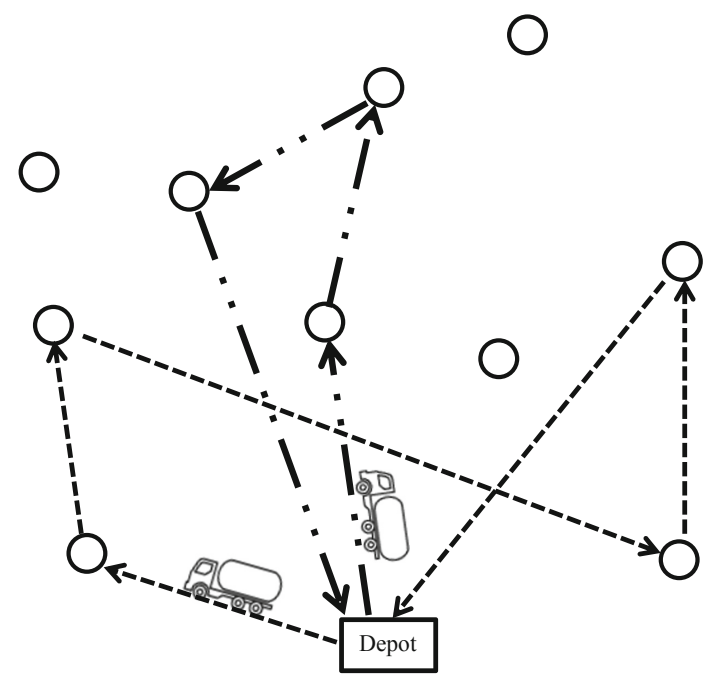

Fig. 2. Problem schematic to define the parameters.

S Set of sub-tours

$\mathrm{O}$ Index of refilling station

Parameters

$\mathrm{d}(\mathrm{i}, \mathrm{j}) \quad$ Length of $\operatorname{arc}\left(\mathrm{n}_{\mathrm{i}}, \mathrm{n}_{\mathrm{j}}\right)$

$w(i, j) \quad$ Amount of water needed for $\operatorname{arc}\left(n_{i}, n_{j}\right)$

TT(k) Total time of availability of truck k

$\mathrm{t}(\mathrm{i}, \mathrm{j}, \mathrm{k}) \quad$ Time needed truck $\mathrm{k}$ traverses $\operatorname{arc}\left(\mathrm{n}_{\mathrm{i}}, \mathrm{n}_{\mathrm{j}}\right)$

$\mathrm{s}(\mathrm{i}, \mathrm{j}, \mathrm{k})$ Time needed truck $\mathrm{k}$ services $\operatorname{arc}\left(\mathrm{n}_{\mathrm{i}}, \mathrm{n}_{\mathrm{j}}\right)$

Cap Capacity of trucks

M Big number

Variables

$\mathrm{x}(\mathrm{i}, \mathrm{j}, \mathrm{k}) \quad$ A binary decision variable representing a dispatch decision 1 if and only if truck $\mathrm{k}$ traverses $\operatorname{arc}\left(\mathrm{n}_{\mathrm{i}}, \mathrm{n}_{\mathrm{j}}\right)$, and 0 otherwise

$\mathrm{y}(\mathrm{i}, \mathrm{j}, \mathrm{k}) \quad$ A binary decision variable representing a service decision 1 if and only if truck k services $\operatorname{arc}\left(\mathrm{n}_{\mathrm{i}}, \mathrm{n}_{\mathrm{j}}\right), 0$ otherwise

AT $(\mathrm{i}, \mathrm{j}, \mathrm{k}) \quad$ Truck k's arrival time to $\operatorname{arc}\left(\mathrm{n}_{\mathrm{i}}, \mathrm{n}_{\mathrm{j}}\right)$

$\mathrm{B}(\mathrm{i}, \mathrm{j}) \quad$ Time to start servicing $\operatorname{arc}\left(\mathrm{n}_{\mathrm{i}}, \mathrm{n}_{\mathrm{j}}\right)$

$\mathrm{z}_{1} \quad$ Variable related to objective function

$\mathrm{U} \quad$ Binary variable related to impermissible sub-tours

L Binary variable related to impermissible sub-tours. 
The mathematical equations associated with the problem could be summarized as follow:

$$
\begin{aligned}
& \min \sum_{\mathrm{k}=1}^{\mathrm{m}} \sum_{\left(\mathrm{n}_{\mathrm{i}}, \mathrm{n}_{\mathrm{j}}\right) \in \mathrm{A}} \mathrm{d}_{\mathrm{ij}} \mathrm{X}_{\mathrm{ijk}} \\
& \sum_{n_{j}:\left(n_{j}, n_{i}\right) \in A} X_{j i k}=\sum_{n_{j}:\left(n_{i}, n_{j}\right) \in A} X_{i j k} \forall k \in K, n_{i} \in N \\
& \sum_{\mathrm{k}=1}^{\mathrm{m}}\left(\mathrm{Y}_{\mathrm{ijk}}+\mathrm{Y}_{\mathrm{jik}}\right)=1 \forall\left(\mathrm{n}_{\mathrm{i}}, \mathrm{n}_{\mathrm{j}}\right),\left(\mathrm{n}_{\mathrm{j}}, \mathrm{n}_{\mathrm{i}}\right) \in \mathrm{R}_{1} \\
& \sum_{\mathrm{k}=1}^{\mathrm{m}} \mathrm{Y}_{\mathrm{ijk}}=1 \forall\left(\mathrm{n}_{\mathrm{i}}, \mathrm{n}_{\mathrm{j}}\right) \in \mathrm{R}_{2} \\
& \mathrm{X}_{\mathrm{ijk}} \geq \mathrm{Y}_{\mathrm{ijk}} \forall\left(\mathrm{n}_{\mathrm{i}}, \mathrm{n}_{\mathrm{j}}\right) \in \mathrm{A} \\
& \sum_{\left(\mathrm{n}_{\mathrm{j}}, \mathrm{n}_{\mathrm{i}}\right) \in \mathrm{A}} \mathrm{w}_{\mathrm{ij}} \mathrm{Y}_{\mathrm{ijk}} \leq \mathrm{c} \forall \mathrm{k} \in \mathrm{K} \\
& \mathrm{At}_{\mathrm{ijk}}+\mathrm{S}_{\mathrm{ijk}} \mathrm{Y}_{\mathrm{ijk}}+\mathrm{t}_{\mathrm{ijk}} \mathrm{X}_{\mathrm{ijk}} \leq \mathrm{M}\left(1-\mathrm{X}_{\mathrm{ijk}}\right)+\mathrm{At}_{\mathrm{jik}} \quad \forall \mathrm{k} \in \mathrm{K}, \text { all }\left(\mathrm{n}_{\mathrm{i}}, \mathrm{n}_{\mathrm{j}}\right) \\
& \mathrm{At}_{\mathrm{jik}} \leq \mathrm{M}\left(1-\mathrm{Y}_{\mathrm{ijk}}\right)+\mathrm{B}_{\mathrm{ij}} \quad \forall \mathrm{k} \in \mathrm{K} \\
& \sum_{\left(\mathrm{n}_{\mathrm{i}}, \mathrm{n}_{\mathrm{j}}\right) \in \mathrm{A}}\left(\mathrm{S}_{\mathrm{ijk}} \mathrm{Y}_{\mathrm{ijk}}+\mathrm{t}_{\mathrm{ijk}} \mathrm{X}_{\mathrm{ijk}}\right)<\mathrm{T}_{\mathrm{k}} \forall \mathrm{k} \in \mathrm{K} \\
& \sum_{\mathrm{n}_{\mathrm{j}}:\left(\mathrm{n}_{\mathrm{o}}, \mathrm{n}_{\mathrm{j}}\right) \in \mathrm{A}}\left(\mathrm{X}_{0 \mathrm{jk}}\right)=1 \forall \mathrm{k} \in \mathrm{K} \\
& \sum_{\mathrm{n}_{\mathrm{i}}:\left(\mathrm{n}_{\mathrm{i}}, \mathrm{n}_{\mathrm{o}}\right) \in \mathrm{A}}\left(\mathrm{X}_{\mathrm{i} \text { ok }}\right)=1 \forall \mathrm{k} \in \mathrm{K} \\
& \sum_{\mathrm{n}_{\mathrm{i}}, \mathrm{n}_{\mathrm{j}} \in \mathrm{S}} \mathrm{x}_{\mathrm{ijk}}=|\mathrm{S}|-1+|\mathrm{N}|^{2} \mathrm{u}_{\mathrm{k}}^{\mathrm{S}}, \forall \mathrm{S} \subseteq \mathrm{N} \backslash\{\mathrm{o}\} ; \mathrm{S} \neq \emptyset ; \forall \mathrm{k} \in \mathrm{K} \\
& \sum_{\mathrm{n}_{\mathrm{i}} \in \mathrm{S}} \sum_{\mathrm{n}_{\mathrm{j}} \notin \mathrm{S}} \mathrm{x}_{\mathrm{ijk}} \geq 1-\mathrm{l}_{\mathrm{k}}^{\mathrm{S}}, \forall \mathrm{S} \subseteq \mathrm{N} \backslash\{\mathrm{o}\} ; \mathrm{S} \neq \emptyset ; \forall \mathrm{k} \in \mathrm{K} \\
& \mathrm{u}_{\mathrm{k}}^{\mathrm{S}}+\mathrm{l}_{\mathrm{k}}^{\mathrm{S}} \leq 1, \forall \mathrm{S} \subseteq \mathrm{N} \backslash\{\mathrm{o}\} ; \mathrm{S} \neq \emptyset ; \forall \mathrm{k} \in \mathrm{K}
\end{aligned}
$$




$$
\begin{gathered}
\mathrm{u}_{\mathrm{k}}^{\mathrm{S}}, \mathrm{l}_{\mathrm{k}}^{\mathrm{S}} \text { Binary, } \forall \mathrm{S} \subseteq \mathrm{V} \backslash\{\mathrm{o}\} ; \mathrm{S} \neq \emptyset ; \forall \mathrm{k} \in \mathrm{K} \\
\mathrm{X}_{\mathrm{ijk}}, \mathrm{Y}_{\mathrm{ijk}} \text { Binary }
\end{gathered}
$$

Where:

- Equation (1) represents the objective function which calculates the total distance traveled by the homogeneous water truck fleet.

- Equation (2) is a flow conservation constraint.

- Constraint (3) ensures that water truck k services to unidirectional road just once.

- Constraint (4) guarantees that water truck k services to each two-way road back and forth.

- Constraint (5) ensures that the number of services is equal or less than the number of traverses. Constraint (6) indicates that total water consumption in each tour is less than water truck's capacity. Terms (7), (8) and (9) are related to time window constraints.

- Constraint (10) requires that tour begins from depot.

- Constraint (11) indicates that the model is not in open category ARP.

- Constraint (12), (13), (14) and (15) are constraints for sub-tour elimination.

- Constraint (16) defines the decision variables.

With respect to the nature of the problem (limited number of vehicles, nodes and arcs) and type of problem (mix integer linear programming model), the General Algebraic Modelling System (GAMS) is selected to deal with this optimization problem. In addition, since there is at least one binary variable in the model, solving is done by MIP and appropriate solver is CPLEX. GAMS version used in this research is 24.1.2 and the configuration of the system consists of Intel Core i3-2370M CPU @ 2.4 GHz and 2 GB DDR3 SD-RAM. Among different solvers, CPLEX with the best time (0.26 s) showed the highest speed.

The GAMS as high-level modelling software for mathematical programming and optimization, includes a language compiler and integrated high-performance solvers. The GAMS is tailored for complex, large scale modelling applications, and allows designers to build large maintainable models that can be adapted quickly to new situations. The GAMS is specifically designed for modelling linear, nonlinear and mixed integer optimization problems. Different solvers and portfolio of GAMS are summarized in Table 4. 
Table 4. Solvers and portfolio of the GAMS

\begin{tabular}{l|l}
\hline Solver & Portfolio \\
\hline $\begin{array}{l}\text { Linear Programing/Mixed } \\
\text { Integer }\end{array}$ & CPLEX/GUROBI/MOSEK/XPRESS \\
$\begin{array}{l}\text { Programing/Quadratically } \\
\text { constrained program } \\
\text { (QCP)/Mixed Integer QCP }\end{array}$ & \\
\hline Non Linear Programing (NLP) & CONOPT/IPOPTH/KNITRO/MINOS/SNOP \\
\hline Mixed Integer NLP (MINLP) & ALPHAECP/ANTIGONE/BARON/DICOPT/OQNLP/SBB \\
\hline $\begin{array}{l}\text { Mixed complementarity problem } \\
\text { (MCP)/Mathematical program } \\
\text { with equilibrium constraints } \\
\text { (MPEC)/Constrained Nonlinear }\end{array}$ & -- \\
System (CNS)
\end{tabular}

\section{Results Analysis}

In order to confirm the ability of the GAMS in dealing with the water truck routing in open pit mines, a graph with 6 nodes is assumed as the case study. Node O indicates depot and refilling point that located in depot. Following matrix shows the existing roads including unidirectional, two ways and combinational roads. A fleet with 3 water trucks and 300 units in capacity is considered (Fig. 3).

So, the graph network would be as follows which has 5 arcs with double sided demand and 3 arcs with one way demand (Fig. 4).

The matrices, graphs and Eqs. 1-16 are dealt with the GAMS to find the optimized solution for the problem. After solving the problem, the optimal value of objective function was equal to 229.274 distance unit and the optimized tours for each water truck are shown in Fig. 5. For instance, this figure shows that truck 2 would not pass the point 4 in the optimized design. In Fig. 5, black lines show the two-way paths and blue-lines show unidirectional paths.

Also, the optimized parameters are shown in Table 6. As shown in this table, the obtained results for the optimal tour of Fig. 5 states that:

- The minimum and maximum length of arc will be passed by truck 1 between nodes 2 and 3 (10.134) and between nodes 5 and 2 (11.662) respectively.

- The minimum required amount of water is for truck 1 in the route between nodes 5 and 2 (12.218) while the maximum required amount of water is for truck 2 between nodes 1 and 3 (28.124).

- Finally, the minimum service time is 5.085 from nodes 1 to node 3 by truck 2 and the maximum service time will be taken by truck 3 when servicing path between nodes 4 and 6.

Other details about the optimized results could be found in Table 5 as well. 


\begin{tabular}{|l|l|l|l|l|l|}
\hline 0 & 1 & 1 & 1 & 1 & 1 \\
\hline 1 & 0 & 1 & 1 & 1 & 1 \\
\hline 1 & 1 & 0 & 1 & 1 & 1 \\
\hline 0 & 1 & 0 & 0 & 1 & 1 \\
\hline 1 & 1 & 1 & 1 & 0 & 1 \\
\hline 0 & 0 & 0 & 1 & 1 & 0 \\
\hline
\end{tabular}

Existing arcs matrix

\begin{tabular}{|l|l|l|l|l|l|}
\hline 0 & 0 & 1 & 0 & 0 & 0 \\
\hline 0 & 0 & 1 & 0 & 1 & 0 \\
\hline 1 & 1 & 0 & 0 & 1 & 0 \\
\hline 0 & 0 & 0 & 0 & 0 & 1 \\
\hline 0 & 1 & 1 & 0 & 0 & 0 \\
\hline 0 & 0 & 0 & 1 & 0 & 0 \\
\hline
\end{tabular}

Existing two ways arcs matrix

\begin{tabular}{|l|l|l|l|l|l|}
\hline 0 & 0 & 0 & 0 & 0 & 0 \\
\hline 0 & 0 & 0 & 0 & 0 & 1 \\
\hline 0 & 0 & 0 & 1 & 0 & 0 \\
\hline 0 & 1 & 0 & 0 & 0 & 0 \\
\hline 0 & 0 & 0 & 0 & 0 & 0 \\
\hline 0 & 0 & 0 & 0 & 0 & 0 \\
\hline
\end{tabular}

Existing unidirectional arcs matrix

\begin{tabular}{|l|l|l|l|l|l|}
\hline 0 & 0 & 1 & 0 & 0 & 0 \\
\hline 0 & 0 & 1 & 0 & 1 & 1 \\
\hline 1 & 1 & 0 & 1 & 1 & 0 \\
\hline 0 & 1 & 0 & 0 & 0 & 1 \\
\hline 0 & 1 & 1 & 0 & 0 & 0 \\
\hline 0 & 0 & 0 & 1 & 0 & 0 \\
\hline
\end{tabular}

Combinational matrix

Fig. 3. Existing arcs for the defined case study. 


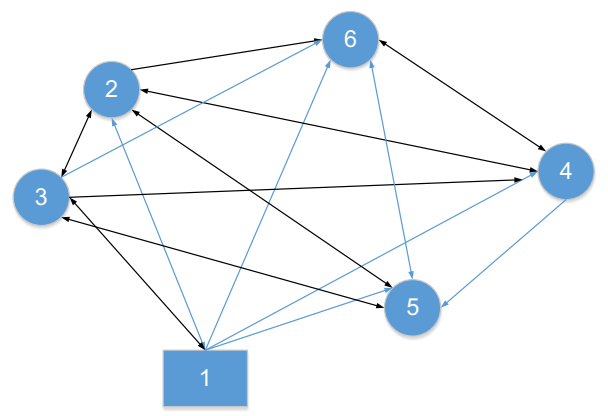

Fig. 4. The graph network for the defined case study.

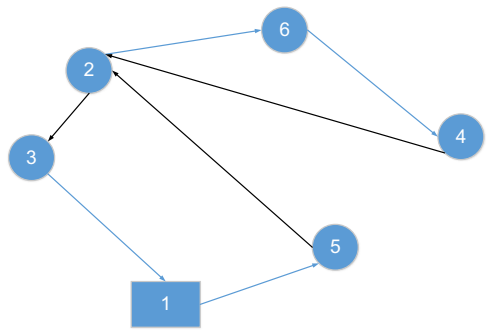

Optimal tour for water truck 1
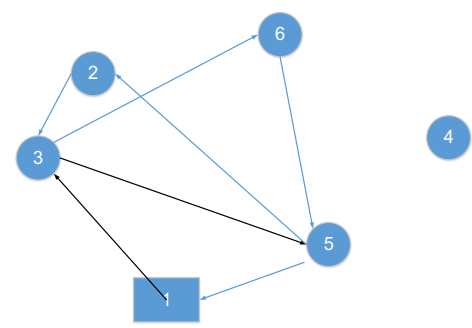

Optimal tour for water truck 2

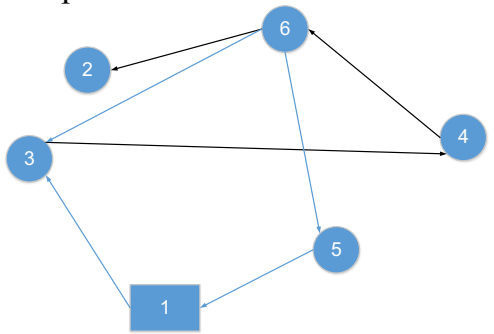

Optimal tour for water truck 3

Fig. 5. The optimized tours for trucks. 
Table 5. The optimized parameters for the water truck routing problem

\begin{tabular}{l|l|l|l|l|l}
\hline Serves arc & $\mathrm{d}(\mathrm{i}, \mathrm{j})$ & $\mathrm{W}(\mathrm{i}, \mathrm{j})$ & $\mathrm{S}(\mathrm{i}, \mathrm{j})$ & AT $(\mathrm{i}, \mathrm{j})$ & Truck \\
\hline $2-5$ & 11.662 & 12.218 & 5.593 & 2.269 & 1 \\
\hline $3-2$ & 10.134 & 17.106 & 5.734 & 2.145 & 1 \\
\hline $2-4$ & 10.871 & 19.121 & 5.348 & 3.543 & 1 \\
\hline $5-3$ & 10.319 & 16.226 & 5.155 & 2.348 & 2 \\
\hline $3-1$ & 11.101 & 28.124 & 5.085 & 2.0931 & 2 \\
\hline $4-3$ & 11.279 & 20.241 & 5.259 & 2.999 & 3 \\
\hline $6-4$ & 11.008 & 18.232 & 5.701 & 3.214 & 3 \\
\hline
\end{tabular}

\section{Conclusion}

This paper presents a methodological approach for optimization of the water truck routing problem using a system approach tool. Expansion of mineral extraction and subsequently, surface mining leads to dust emission containing Silica in mines and their suburbs. Inhaling of dust containing Silica as a mineral with the most plenty in the earth causes respiratory diseases such as silicosis and lung cancer. Therefore, the main motive of this research is to pay special attention to the issue of sustainability in mines with an environmental approach and protecting human health. A comprehensive literature survey presented to conclude that this piece of research will fill a systematic gap in the literature from transport and logistics point of view. A mathematical model of nodes, paths, trucks, depot and refilling is developed using a matrix approach and the objective function and constraint equations are generated in detail. The General Algebraic Modelling System Approach (GAMS) is used to deal with the optimization problem and the obtained results show the effectiveness of the used method in finding the optimal tours for each truck, the minimum length of the arcs, the minimum amount of water for servicing the routes, and the minimum service time required for each route. The study confirms the capability of the proposed method for the future research studies in the field (e.g. effect of environmental parameters, soil characteristics, and human behavior in optimization of water truck routing problem in open pit mines).

\section{References}

Archetti, C., Feillet, D., Hertz, A., Speranza, M.G.: The undirected capacitated arc routing problem with profits. Comput. Oper. Res. 37, 1860-186 (2010)

Armas, J.D., Ferrer, A., Juan, A.A., Lalla-Ruiz, E.: Modeling and solving the non-smooth arc routing problem with realistic soft constraints. Expert Syst. Appl. 98, 205-220 (2018)

Assad, A.A., Golden, B.L., Pearn, W.L.: Transforming arc routing into node routing problems. Comput. Oper. Res. 14(4), 285-288 (1987)

Babaee Tirkolaee, E., Alinaghian, M., Rahmani Hosseinabadi, A.A., Bakhshi Sasi, M., Sangaiah, A.K.: An improved ant colony optimization for the multi-trip Capacitated Arc Routing Problem. Comput. Electr. Eng. 77, 1-15 (2018) 
Babaee Tirkolaee, E., Mahdavi, I., Seyyed Esfahani, M.M.: A robust periodic capacitated arc routing problem for urban waste collection considering drivers and crew's working time. Waste Manage. 76, 138 (2018b).

Babaee Tirkolaee, E., Rahmani Hosseinabadi, A.A., Soltani, M., Sangaiah, A.K., Wang, J.: A hybrid genetic algorithm for multi-trip green capacitated arc routing problem in the scope of urban services. Sustainability 10, 1366 (2018c)

Babaee Tirkolaei, E., Goli, A., Malekalipour Kordestanizadeh, R.: A robust bi-objective multitrip periodic capacitated arc routing problem for urban waste collection using a multi-objective invasive weed optimization. Waste Manage. Res. 37, 1-13 (2019)

Belenguer, J.M., Benavent, E.: A cutting plane algorithm for the capacitated arc routing problem. Comput. Oper. Res. 30, 705-728 (2003)

Benavent, E., Soler, D.: The directed rural postman problem with turn penalties. Transp. Sci. 33, 408-418 (1999)

Beraldi, P., Bruni, M.E., Laganà, D., Musmanno, R.: The mixed capacitated general routing problem under uncertainty. Eur. J. Oper. Res. 240, 382-392 (2015)

Christofidrordes, N.: The optimum traversal of a graph. Omega 1, 719-732 (1973)

Constantino, M., Gouveia, L., Mourão, M.C., Nunes, A.C.: The mixed capacitated arc routing problem with non-overlapping routes. Eur. J. Oper. Res. 24, 445-456 (2015)

Dror, M., Leung, J.M.Y.: Combinatorial optimization in a cattle yard: feed distribution, vehicle scheduling, lot sizing and dynamic pen assignment. In: Yu, G. (ed.) Industrial Applications of Combinatorial Optimization, vol. 16, pp. 142-171, Kluwer (1998)

Dror, M., Leung, J.M.Y.: Combinatorial optimization in a cattle yard: Feed distribution, vehicle scheduling, lot sizing and dynamic pen assignment. Ind. Appl. Comb. Optim. 16, 142-171 (1998)

Dror, M., Stern, H., Trudeau, P.: Postman tour on a graph with precedence relation on arcs. Networks 17, 283-294 (1978)

Edmonds, J., Johnson, E.L.: Matching, euler tours and the chinese postman. Math. Program. 5(1), 88-124 (1973)

Eglese, R.W.: Routing winter gritting vehicle. Discret. Appl. Math. 48, 231-244 (1994)

Eiselt, H.A., Gendreau, M., Laporte, G.: Arc routing-problems, part I: the Chinese postman problem. Oper. Res. 43(2), 231-242 (1995)

Eiselt, H.A., Gendreau, M., Laporte, G.: Arc routing-problems, part II: the rural postman problem. Oper. Res. 43(3), 399-414 (1995)

Ghiani, G., Improta, G., Laporte, G.: The capacitated arc routing problem with intermediate facilities. Networks 37, 134-143 (2001)

Golden, B.L., Wong, R.T.: Capacitated arc routing problems. Networks 11, 305-315 (1981)

Golden, B.L., Bruce, L., Raghavan, S., Wasil Edward, A.: The Vehicle Routing Problem: Latest Advances and New Challenges. Springer, Boston (2008). https://doi.org/10.1007/978-0-387$77778-8$

Gonzalez, S., Juan, A., Riera, D., Elizondo, M., Ramos, J.: A simheuristic algorithm for solving the arc routing problem with stochastic demands. J. Simul. 12(1), 53-66 (2016)

Gupta, P., Mehlawat, M. K., Aggarval, U., Charles, V.: An integrated AHP-DEA multi-objective optimization model for sustainable transportation in mining industry. In: Resource Policy in Press (2018)

Hedetniemi, S.: On minimum walks in graphs. Naval Res. Logist. Wiley New York 15(3), 453-458 (1968)

Karaoglan, I., Altiparmak, E.: A memetic algorithm for the capacitated location-routing problem with mixed backhauls. Comput. Oper. Res. 55, 200-216 (2013)

Khajepoura, A., Sheikhmohammady, M., Nikbakhsh, E.: Field path planning using capacitated arc routing problem. Comput. Electron. Agric. 173, 105401 (2020) 
King, B., Goycoolea, M., Newman, A.: Optimizing the open pit-to-underground mining transition. Eur. J. Oper. Res. 257, 297-309 (2016)

Krushinsky, D., Woensel, T.V.: Discrete optimization an approach to the asymmetric multi-depot capacitated arc routing problem. Eur. J. Oper. Res. 244, 100-110 (2015)

Kwan, M.K.: Graphic programming using odd or even points. Chin. Math. 1, 273-277 (1962)

Letchford, A.N., Eglese, R.W.: The rural postman problem with deadline classes. Eur. J. Oper. Res. 105, 390-400 (1998)

Mico, J.C., Soler, D.: The capacitated general windy routing problem with turn penalties. Oper. Res. Lett. 39, 265-271 (2011)

Monroy, I.M., Amaya, C.A., Langevin, A.: The periodic capacitated arc routing problem with irregular services. Discret. Appl. Math. 161, 691-701 (2013)

Mullaseril, P.A.: Capacitated rural postman problem with time windows and split delivery. Ph.D. thesis, MIS Department, University of Arizona (1996)

Newman, A.M., Rubio, E., Caro, R., Weintraub, A., Eurek, K.: A Review of Operations Research in Mine Planning. Interfaces 40, 222-224 (2010)

Sachs, H., Stiebitz, M., Wilson, R.J.: An historical note: Euler's Königsberg letters. J. Graph Theory 12(1), 133-139 (1988)

Willemse, E.J., Joubert, J.W.: Efficient local search strategies for the Mixed Capacitated Arc Routing Problems under Time restrictions with Intermediate Facilities. Comput. Oper. Res. 105, 203 (2019)

Wohlk, S.: A decade of capacitated arc routing. Oper. Res. Comput. Sci. Interfaces 43, 29-48 (2008) 